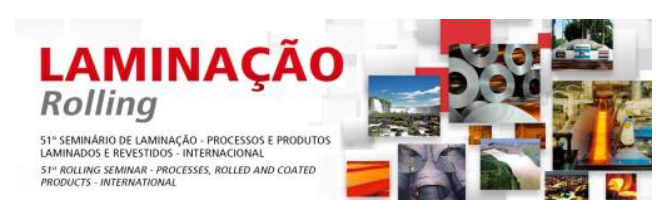

\title{
SIMPLY THE BEST SBQ PRODUCTION TECHNOLOGY*
}

Filippo Verlezza ${ }^{1}$ Guenther Schnel/2

\section{Abstract}

The 3-roll technology is a recognized process applied to SBQ production. The main aim of this paper is to show the latest developments on this technology including other equipment's that also contributes for a better performance on SBQ coils production.

Keywords: Advanced 3-roll technology; Hydraulic adjustment under load; Special bar quality (SBQ); Sizing technology; Bar in coil production. 


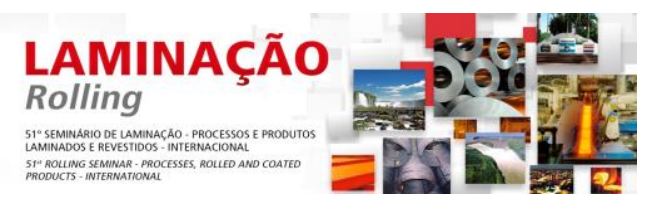

\section{INTRODUCTION}

In 2006 the world wide first 3-roll block for SBQ production with adjustment under load feature went into operation at Deutsche Edelstahlwerke (DEW) SiegenGeisweid/Germany. The great opportunities of the advanced 3-roll technology with the hydraulic adjustment under load feature were obvious. The adjustment under load feature opened up possibilities in most modern SBQ production which were so far not available on the market.

The achievements and results after implementing the $\mathrm{PSM}^{\circledR}$ set a new technology standard. After years of successful operating experience with the advanced 3-roll technology a precise online measuring system in combination with the closed loop size control was added in order to achieve an even higher process transparency. The fully automatic control system is interacting with the hydraulic gap adjustment system of the $\mathrm{PSM}^{\circledR}$ and thus able to directly react online under load on real time measured deviations from the target size.

In combination with the advanced 3-roll technology for most modern SBQ production the $51^{\text {st }}$ pouring reel line of SMS MEER will go in operation in 2013. This pouring reel line is based on 62 years operational experience and represents the most modern pouring reel line technology.

Demands such as improved coil formation and scratch free production of sensitive SBQ products is part of the advanced state of the art pouring reel technology.

The advanced rolling technologies for most modern SBQ production are introduced in the technical paper and operational results shall underline the great potential of this most modern rolling technologies.

\section{1 $\mathrm{PSM}^{\circledR}$ - The advanced 3-roll technology}

A new innovative rolling technology has been introduced in 2006 for special bar quality (SBQ) production and is represented by the Precision Sizing Mill $\left(\mathrm{PSM}^{\circledR}\right)$. This advanced 3-roll technology is already appreciated at several leading SBQ producers in Germany, USA and China and set with its features a new benchmark in the field of SBQ production technology.

The first advanced 3-roll block for wire rod and special bar quality production went into operation at Deutsche Edelstahlwerke Siegen/Germany (DEW Siegen). DEW Siegen is part of the SCHMOLZ + BICKENBACH Group, which with around 11.000 employees are the world's largest manufacturer, processor and distributor of special steel long products. They are rolling at their Siegen works up to $460.000 t$ quality steels, ball bearing steel, spring steel, cold heading steels, high alloyed stainless steels and tools steels per year.

DEW Siegen has a long experience in 3-roll technology since they were the pioneer in 3-roll technology when they started up in 1979 the first industrial used 3-roll blocks for SBQ production. From their start-up experience followed by 25 years' operating experience of three 3-roll blocks of the first generation, DEW Siegen immediately identified one of the great key features of the advanced 3-roll PSM ${ }^{\circledR}$ which was so far not available in the market: the hydraulic adjustment under load feature.

Well aware that, at that time, a pilot installation has some risk and is also challenging, however, due to the outstanding advantages of the $\mathrm{PSM}^{\circledR}$ and the great potential for further improvements of size tolerance they decided for the advanced 3-roll sizing technology supplied by SMS Meer.

\footnotetext{
* Technical contribution to the 51st Rolling Seminar - Processes, Rolled and Coated Products, October $28^{\text {th }}$ to $31^{\text {st }}, 2014$, Foz do Iguaçu, PR, Brazil.
} 


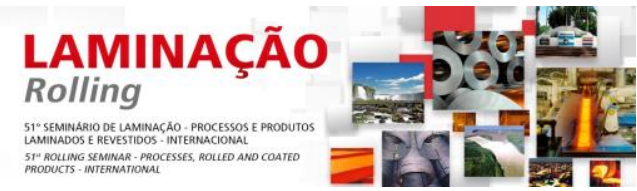

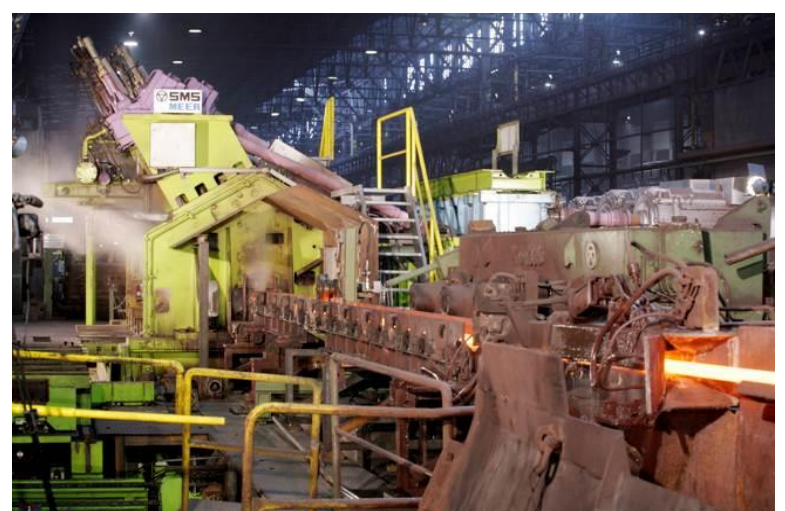

Figure 1: $\mathrm{PSM}^{\circledR}$ 3-roll sizing technology at DEW Siegen/ Germany

The first 3-roll $\mathrm{PSM}^{\circledR}$ went into operation at Deutsche Edelstahlwerke Siegen/Germany [1] in 2006 replacing two of the three existing 3-roll blocks of the first 3-roll generation (Figure 1).

Today all sizes $(\varnothing 22 \mathrm{~mm}-\varnothing 85 \mathrm{~mm})$ are finished successfully with the 6-stand 3-roll $\mathrm{PSM}^{\circledR}$ fulfilling all market requirements with tolerances much better than required. The $\mathrm{PSM}^{\circledR}$ is offering all typical features of the 3-roll sizing technology such as:

- Single pass family rolling (Figure 2)

- for all diameters

- for all steel grades,

- at any time

- Free size rolling ( $9 \%$ of dia. / max. $3 \mathrm{~mm})$

- for infinite sizes (NOT ONLY discrete sizes)

- requires less cassette/roll changes

- leads to less inventory (e.g. rolls, guides)

- Quick cassette changing

- 5 min for individual or all cassettes

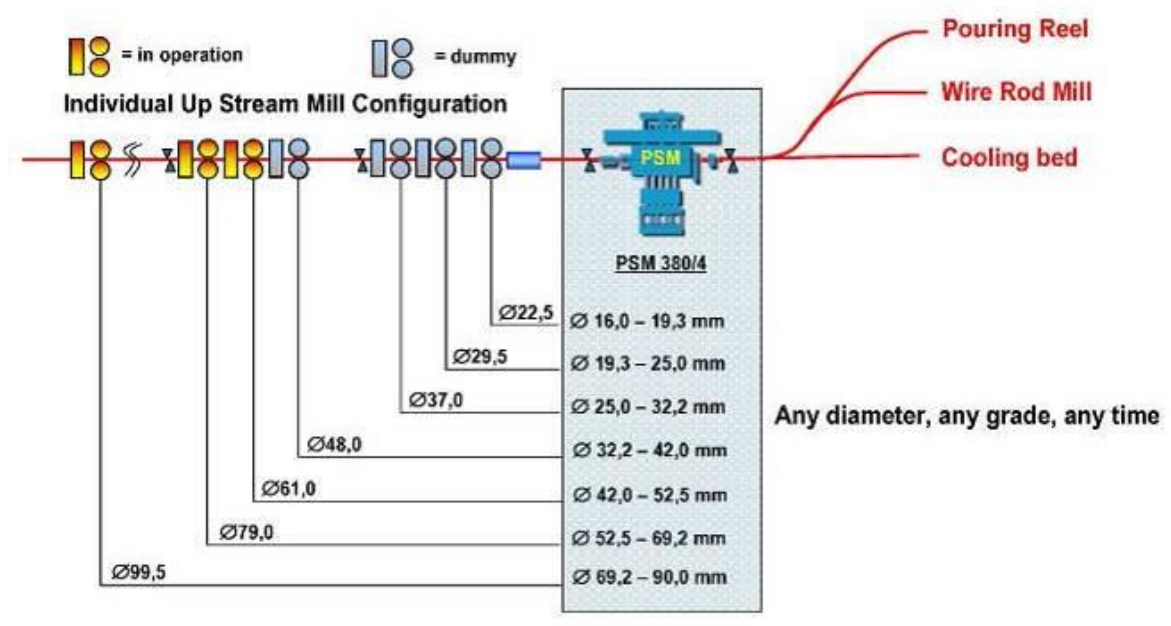

Figure 2: $\mathrm{PSM}^{\circledR}$ - Single Pass Family Rolling Principle

And beside all the typical features of a 3-roll system, one of the outstanding key features in addition to the before mentioned is the real time hydraulic gap adjustment capability under load which makes this machine inimitable. Thanks to the advanced closed loop Technological Control System (TCS) which is also used in other applications such as section mills.

* Technical contribution to the 51st Rolling Seminar - Processes, Rolled and Coated Products, October $28^{\text {th }}$ to $31^{\text {st }}, 2014$, Foz do Iguaçu, PR, Brazil. 


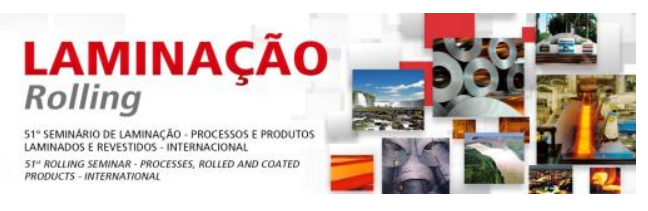

Instead of having a "black box" where only the entry and exit size of the bar can be measured, the TCS offers full process transparency since each individual roll position and in addition, the individual roll force can be detected.

Furthermore the system is able to compensate individual mill spring, feeder variations and bar entering impacts but also is able to balance temperature variations along the bar. Based on the TCS closed loop control system, the system can adapt to different rolling conditions in order to immediately optimize the system for achieving maximum yield on highest availability.

The setup for achieving the required quality of the final product will be planned by a mill configuration tool, the SMS MEERcon PSM®.

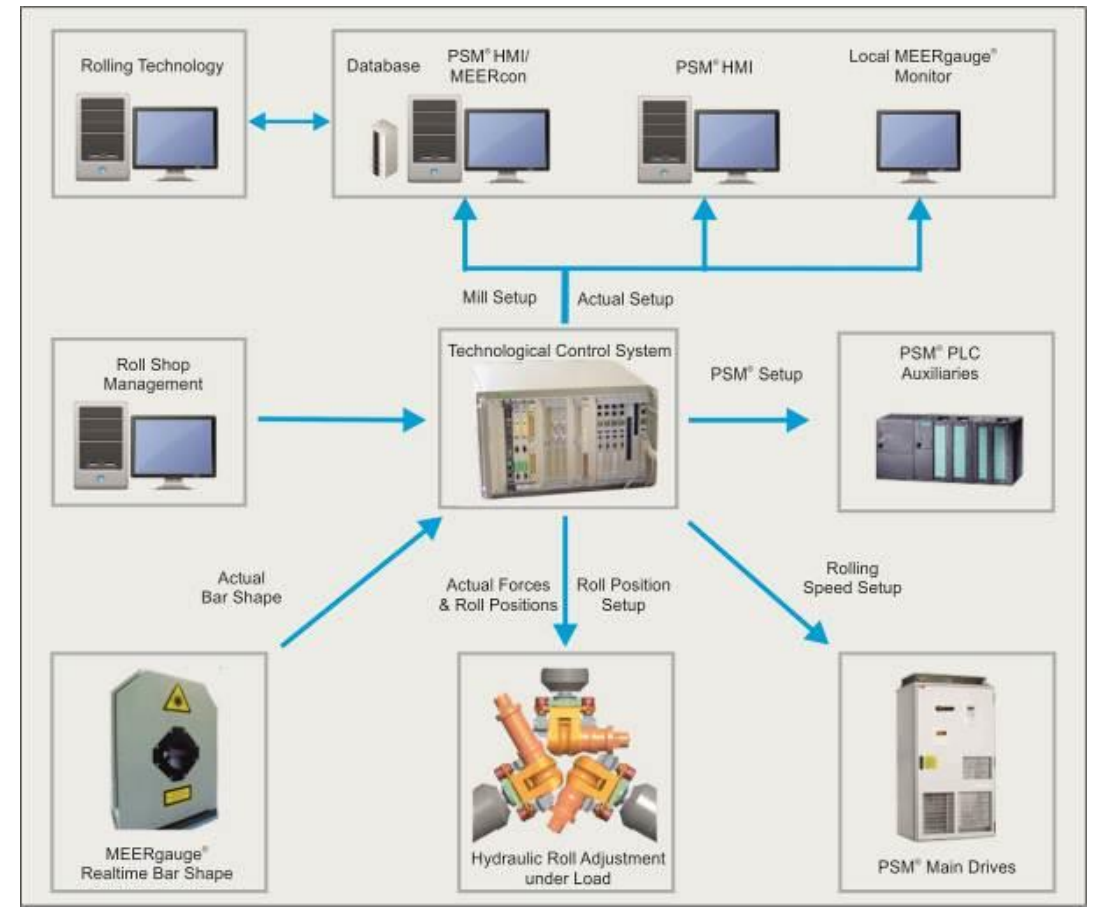

Fig. 3: MEERcon $\mathrm{PSM}^{\circledR}$ - network structure

By means of the MEERcon $\mathrm{PSM}^{\circledR}$ set point selections for the rolling mill can be easily determined and transmitted to the rolling mill automation system via the data network (Figure 3).One of the core elements of the MEERcon $\mathrm{PSM}^{\circledR}$ is a server with a database for mill parameters and result values. The server is interconnected with the basic automation system and can be linked to an unlimited number of workplaces, for example the rolling mill managers, technologists or the roll shop and operator staff.

To quickly determine the rolling data the MEERcon $\mathrm{PSM}^{\circledR}$ system already includes the concepts of rolling technology experience from SMS Meer as pre-setting. For a wide range of special steel grades and individual requirements, the operator is even able to flexibly adapt the setting values by means of a groove editor or create them completely new - from the diameter of the initial pass via the design of the actual groove form up to the calculation of the relevant rolling speeds.

Simulations and visualizations of the systems support the operator at the set-up planning stage.

For each bar the MEERcon $\mathrm{PSM}^{\circledR}$ system stores the setup/calibration data of the rolling mill and the most important rolling results. The data can be evaluated by tables and graphics. In addition, they can be deposited in an empirical database which ensures possible reuse.

* Technical contribution to the 51st Rolling Seminar - Processes, Rolled and Coated Products, October $28^{\text {th }}$ to $31^{\text {st }}, 2014$, Foz do Iguaçu, PR, Brazil. 


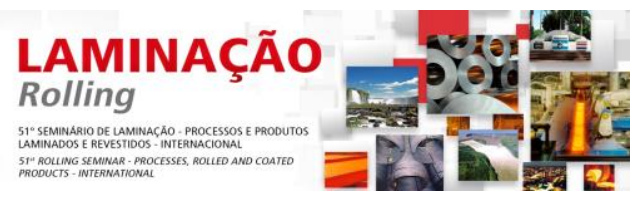

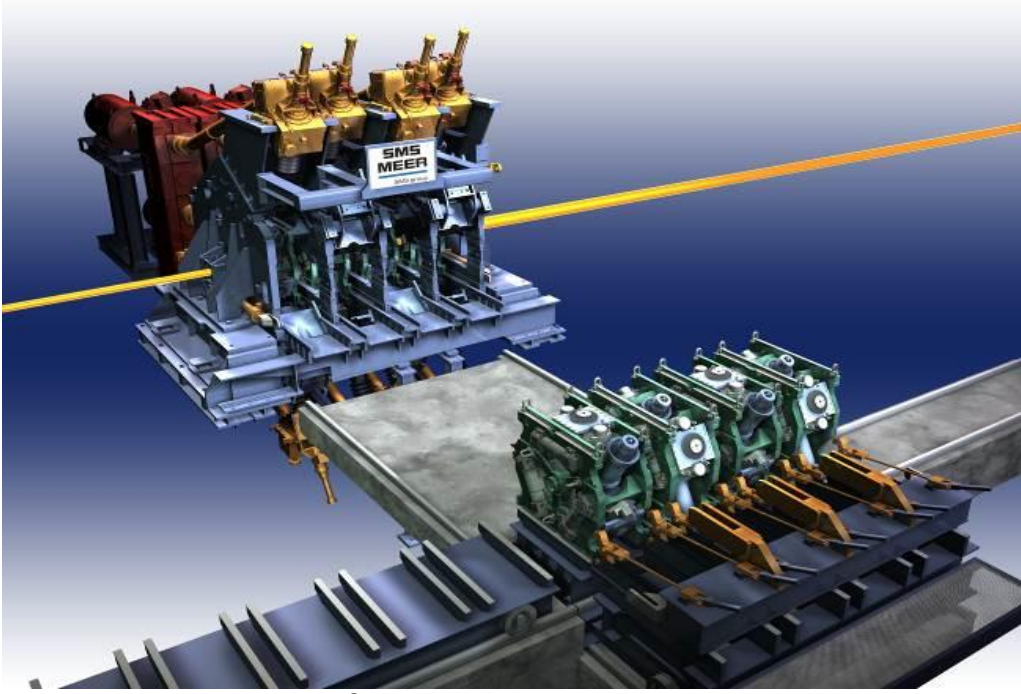

Figure 4: $\mathrm{PSM}^{\circledR}$ - cassette quick change equipment

Another feature is the tool management function which is of tremendous support to the operators and mill management in order to optimize the tool/roll ring costs. The roll ring sets and 3-roll cassettes can be tracked with the MEERcon PSM ${ }^{\circledR}$ system and information about e.g. wear is available. With the aid of the MEERcon $\mathrm{PSM}^{\circledR}$ system, customers are able to fine tune many details in case it is required. These excellent features make the difference to any other system available in the market.

Furthermore the MEERcon PSM® system supplies all data for the setup of the 3-roll cassettes and 3-roll guides in the roll shop.

All cassettes and guides can be transferred directly into the PSM® roll shop by the cassettes changing device and will be prepared off-line shop during rolling (Fig. 4). Due to very tight tolerance requirements the rolls and rollers have to be aligned in the roll shop by means of an optical measurement device (OMD, Fig. 5). The rolls and rollers can be axial and radial positioned with a measuring accuracy of $0,002 \mathrm{~mm}$ by means of a CCD-camera.

In order to further expand the capabilities of the advanced 3-roll technology, SMS Meer and DEW Siegen successfully implemented in joint cooperation a highly dynamic closed loop size control system for the $\mathrm{PSM}^{\circledR}$.

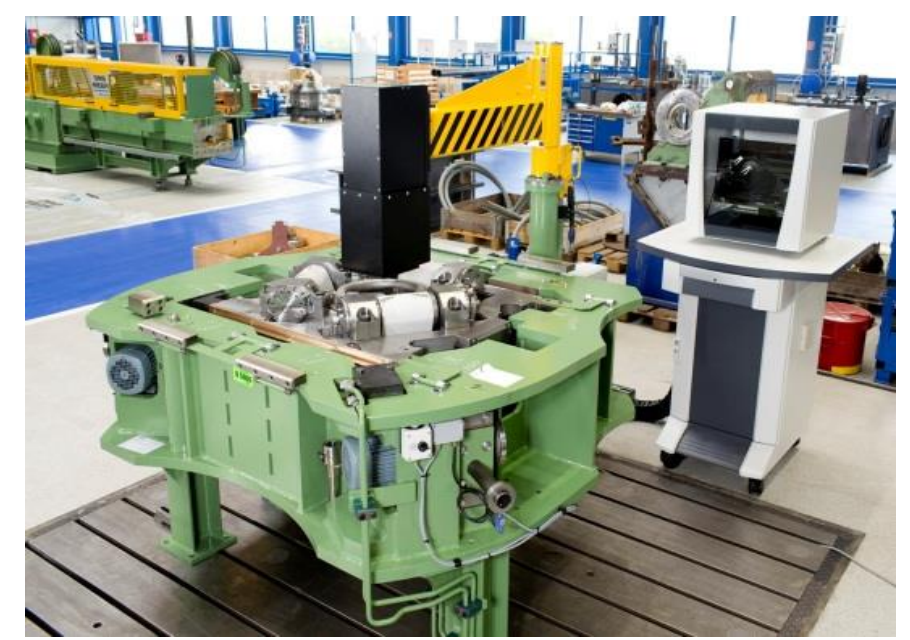

Figure 5: Optical measuring device (OMD)

* Technical contribution to the 51st Rolling Seminar - Processes, Rolled and Coated Products, October $28^{\text {th }}$ to $31^{\text {st }}, 2014$, Foz do Iguaçu, PR, Brazil. 


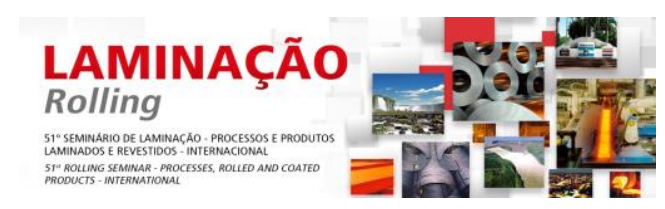

Bar Gauge, the MEERgauge ${ }^{\circledR}$. This is another milestone with regard to the advanced 3-roll technology.

The MEERgauge ${ }^{\circledR}$ (Fig. 6) is installed down stream the 3-roll PSM® directly behind the last 3-roll stand position and is replacing a conventional laser measuring gauge which was working on the shadow measuring method. The shortcoming of the conventional laser gauge is the number of measuring points around the cross section as well as the measuring method due to swiveling laser heads. The MEERgauge $\AA$ at the exit side of the PSM® operates on the basis of the light cut technology (Figure 7). Based on laser/image technology four sensors measure synchronous and contact free the entire cross section of the bar. With a scanning rate of 500 scans per second a true-shape cross-section is established of up to 400 measuring points and displayed with highest precision.

The essential characteristic values of the individual measurements are sent to the Technological Control Centre (TCS) of the PSM® via a direct process field bus connection in real time. The TCS logic analyses the values and assigns relevant adjustment set points for gap corrections if required

Due to a combination of a highly dynamic control system and a true-shape measuring system a fully automatic rolling operation of the PSM ${ }^{\circledR}$ could be successfully realized with the MEERgauge ${ }^{\circledR}$ - independent from the operator.

It is a fully automatic size control system which is able to directly react online under load on real time measured deviations from the target size. It interacts in closed loop mode with the hydraulic gap adjustment system of the PSM®. The basis for the closed loop operation of the rolling gap is the adjustment under load capability.

This is realized by the advanced design of the 3-roll cassette (Figure 8) in combination with the three hydraulic cylinders. The hydraulic cylinders can adjust all three rolls concentrically but in case it is required the system is also able to adjust individually only one or two rolls. Thus symmetrical as well as unsymmetrical positioning adjustments of individual rolls under load offer possibilities for fine optimization of the net shape tolerances.

Another advantage of the design is, that during rolling operation occurring rolling loads are transferred via hydraulic cylinders into the stiff housing of the PSM $\AA^{\text {. Due }}$ to the inimitable design concept of the PSM® wear and maintenance of the cassettes are reduced to an absolute minimum.

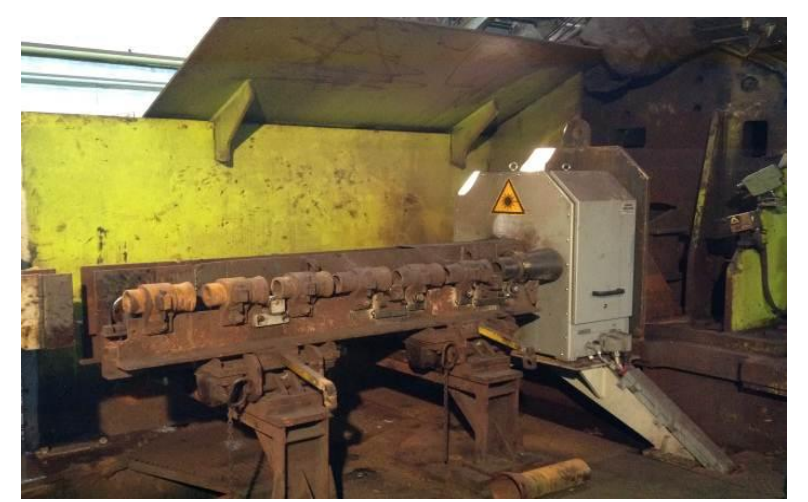

Figure 6: MEERgauge ${ }^{\circledR}$ at the exit side of the 3-roll PSM ${ }^{\circledR}$

\footnotetext{
* Technical contribution to the 51st Rolling Seminar - Processes, Rolled and Coated Products, October $28^{\text {th }}$ to $31^{\text {st }}, 2014$, Foz do Iguaçu, PR, Brazil.
} 


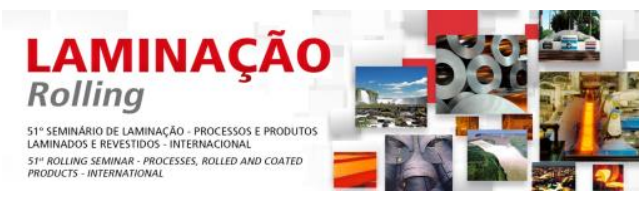
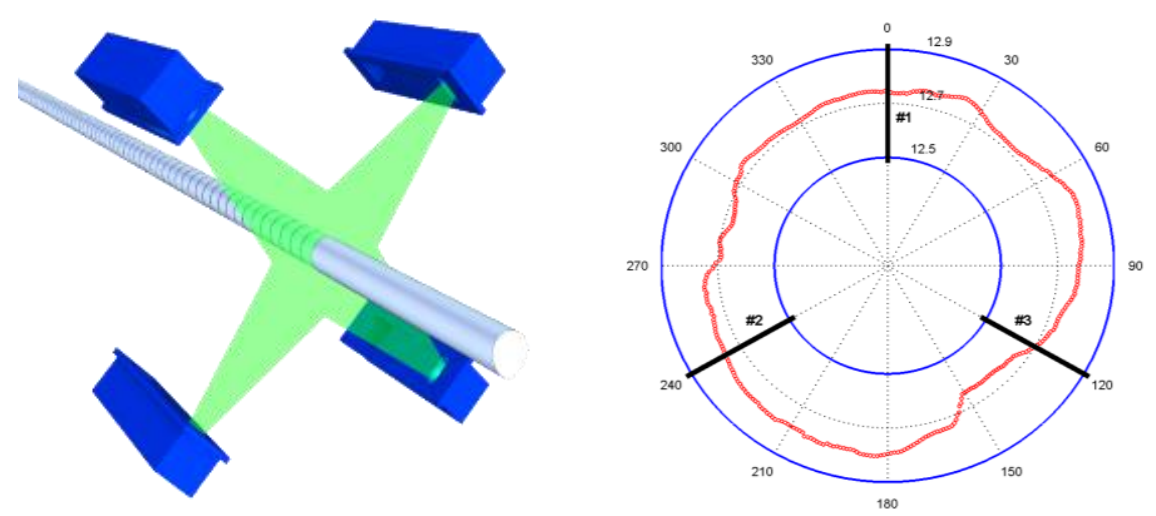

Figure 7: Light-cut sensor arrangement and true-shape cross section display
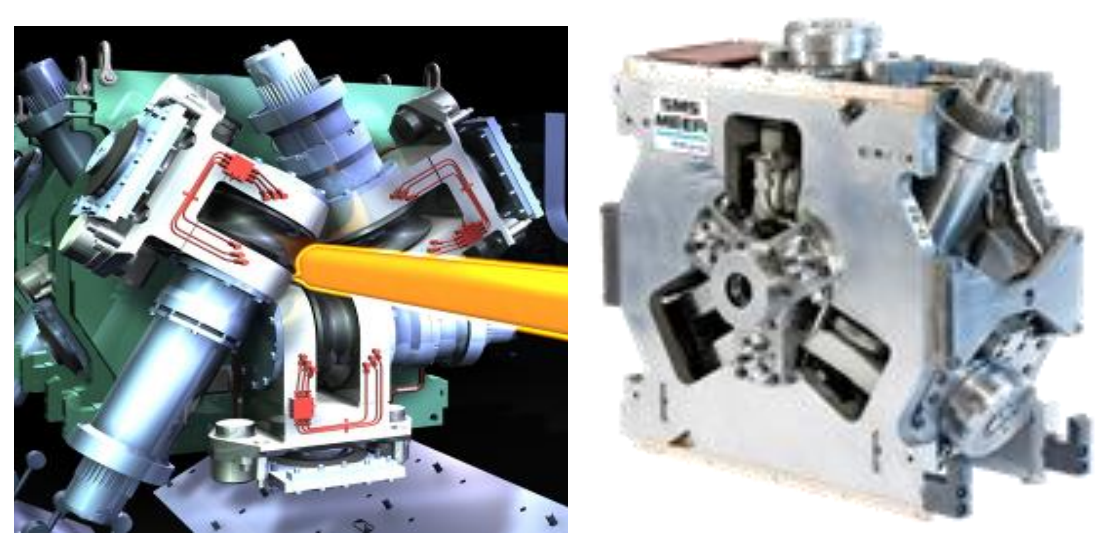

Figure 8: Advanced $\mathrm{PSM}^{\circledR}$ 3-roll cassette

\subsection{Operational Results [2]}

Since the beginning of 2012 the closed loop size control system has been in successful operation - interacting with the new precise true-shape measuring system. The commissioning was uneventful and shortly after start up expectations about the system have already been exceeded. Thanks to the advanced automation level and reliability of the $\mathrm{PSM}^{\circledR}$ excellent results across the whole size range can be reached in fully automatic mode independent of the skill/experience of the operators. Recent achievements are shown in the following screen shots (Figure 9).

\footnotetext{
* Technical contribution to the 51st Rolling Seminar - Processes, Rolled and Coated Products, October $28^{\text {th }}$ to $31^{\text {st }}$, 2014, Foz do Iguaçu, PR, Brazil.
} 


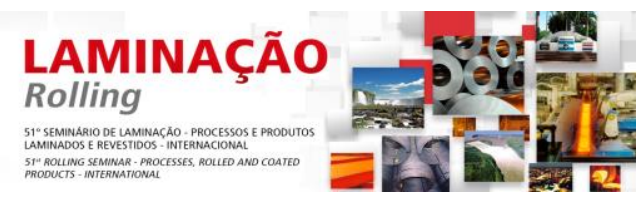

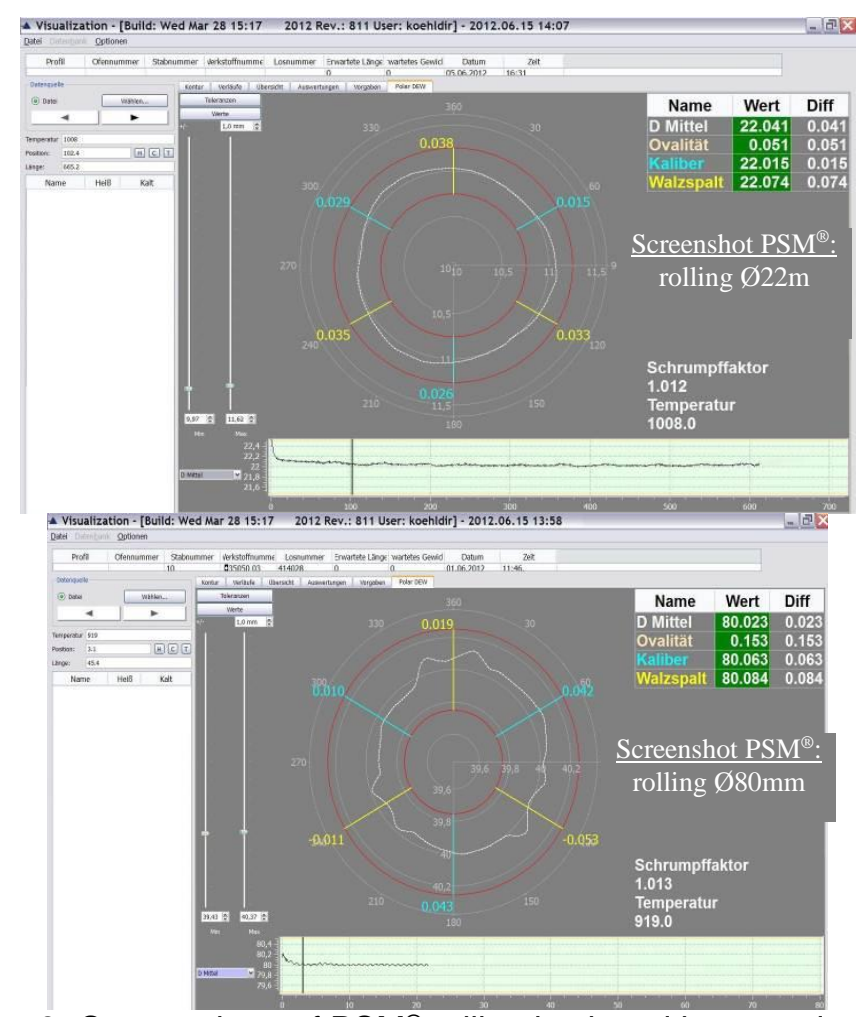

Figure 9: Screen shots of $\mathrm{PSM}^{\circledR}$ rolling in closed loop mode

Required product tolerances are easily fulfilled and even exceeded - even for the most demanding applications tolerances up to 1/8 DIN EN 10060 are achieved reliably and regularly. It goes without saying, that the MEERgauge ${ }^{\circledR}$ does not necessarily help to produce even better tolerances with the $\mathrm{PSM}^{\circledR}$, but does support the operator to react on varying parameters such as feeder size tolerance, temperature variations along the feeder, size and steel grade changes, wear of rolls or even operates the $\mathrm{PSM}^{\circledR}$ in a fully automatic mode.

The advanced 3-roll technology of SMS Meer pays off for their customers. Not only DEW Siegen/Germany benefits since 2006 from the great features of the PSM ${ }^{\circledR}$, since 2009 also Timken/USA established several production and quality records after the installation of the advanced 3-roll technology.

Following the successful installations at DEW Siegen/Germany and Timken/USA seven (7 !) more 3-roll PSM ${ }^{\circledR}$ 's will be installed until 2015.

The next start up of a 3-roll PSM ${ }^{\circledR}$ is scheduled at Steel Dynamics. In summer 2012 Steel Dynamics (SDI), Indiana, USA awarded to SMS Meer the contract to supply a new roughing mill and a new 3-roll Precision Sizing Mill $\left(\mathrm{PSM}^{\circledR}\right)$ to their Pittsboro works. The new rouging mill will be operated in semi-continuous mode consisting of a two-high reversing mill followed by eight rigid housing less stands in $H / V$ configuration which will feed the existing mill.

The advanced 3-roll $\mathrm{PSM}^{\circledR}$ will be installed at the place where a former 3-roll block of the first generation was installed (Figure 10) and will finish all special quality bars in the range from diameter 19-76,2 $\mathrm{mm}$. Those high-quality products are used in a variety of transportation, industrial, energy and automotive applications. The $\mathrm{PSM}^{\circledR}$ package consists of looper, two shear groups and in addition the automatic 3-roll cassette change system, a roll shop for assembly of the 3-roll cassettes and the 3roller guides as well as the technology package MEERCON PSM ${ }^{\circledR}$

\footnotetext{
* Technical contribution to the 51st Rolling Seminar - Processes, Rolled and Coated Products, October $28^{\text {th }}$ to $31^{\text {st }}, 2014$, Foz do Iguaçu, PR, Brazil.
} 


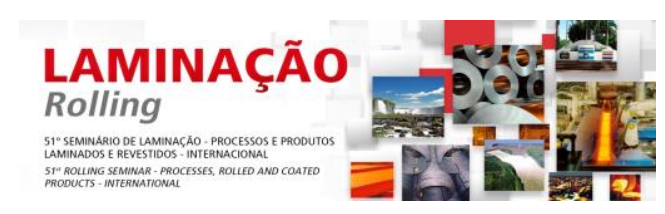

Another 3-roll $\mathrm{PSM}^{\circledR}$ will be installed in a complete new stainless steel rolling mill at Fujian WuHang Stainless Steel Co., Ltd./China. This new rolling mill can be considered as one of the most modern SBQ rolling mills for stainless steel production in the world (Figure 11). All key technologies for producing the high sophisticated grades at FWSS such as austenitic, martensitic and ferritic stainless steel grades will be supplied by SMS Meer. Part of the supply is beside the advanced 3-roll Precision Sizing Mill $\left(\mathrm{PSM}^{\circledR}\right)$, the most modern MEERdrive ${ }^{\circledR}$ wire rod technology, a state of the art pouring reel line but also the complex coil handling system including vertical coil compactors.

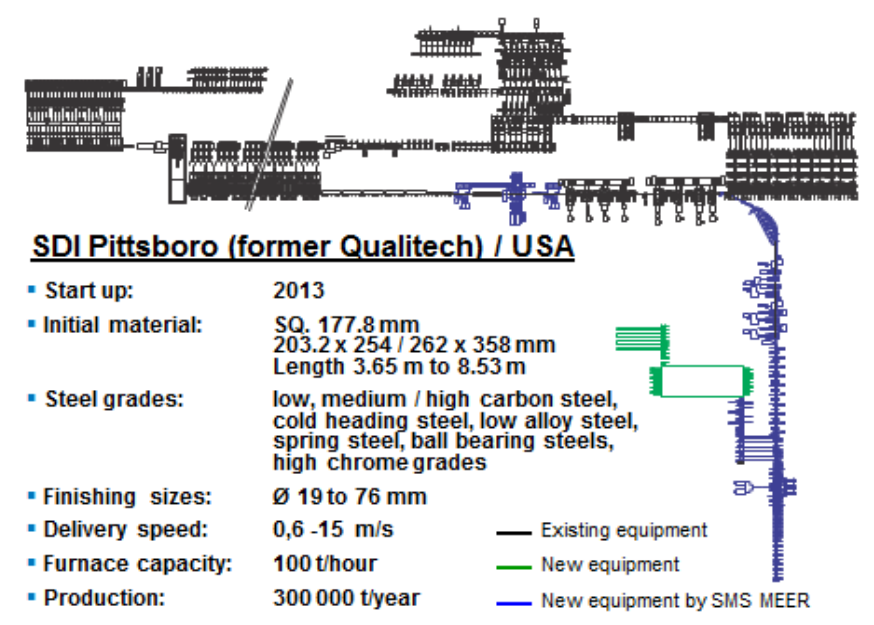

Figure 10: SBQ mill upgrade for Steel Dynamics / USA

\subsection{State of the Art Pouring Reel Technology}

The ideal combination for most modern SBQ production is represented by the advanced $\mathrm{PSM}^{\circledR}$ 3-roll technology and the state of the art pouring reel technology of SMS Meer. Based on 62 years' experience in bar in coil technology the 51st pouring reel line of SMS Meer will be installed at Fujian WuHang Stainless Steel Co., Ltd./China (FWSS).

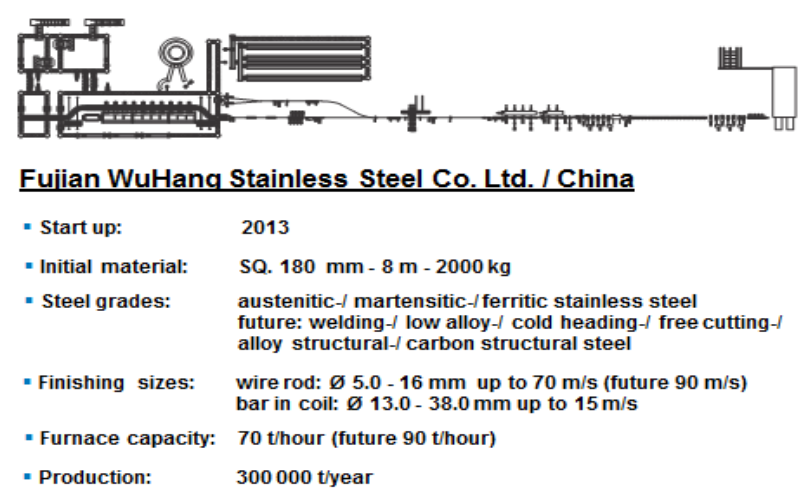

Figure 11: SBQ rolling mill at Fujian WuHang Stainless Steel

The 51st pouring reel line (Figure 12) of SMS Meer is arranged downstream the advanced 3-roll PSM ${ }^{\circledR}$. It is designed to fulfill not only today's market demands with regard to improved coil formation and scratch free production of sensitive SBQ

\footnotetext{
* Technical contribution to the 51st Rolling Seminar - Processes, Rolled and Coated Products, October $28^{\text {th }}$ to $31^{\text {st }}, 2014$, Foz do Iguaçu, PR, Brazil.
} 


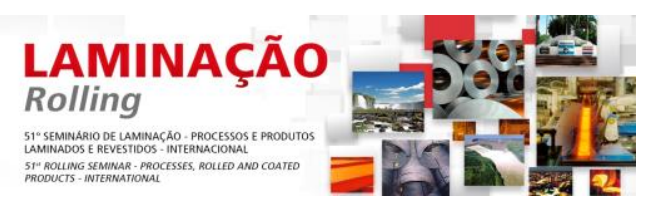

products but is also considered to offer highest flexibility and availability with minimum maintenance requirements.

After the water cooling box an automatic switch guides the bar towards the pouring reel guide trough. For an optimum coiling temperature a water cooling box is installed considering an appropriate equalization length before entering the pouring reel for the wide range of different steel grades.

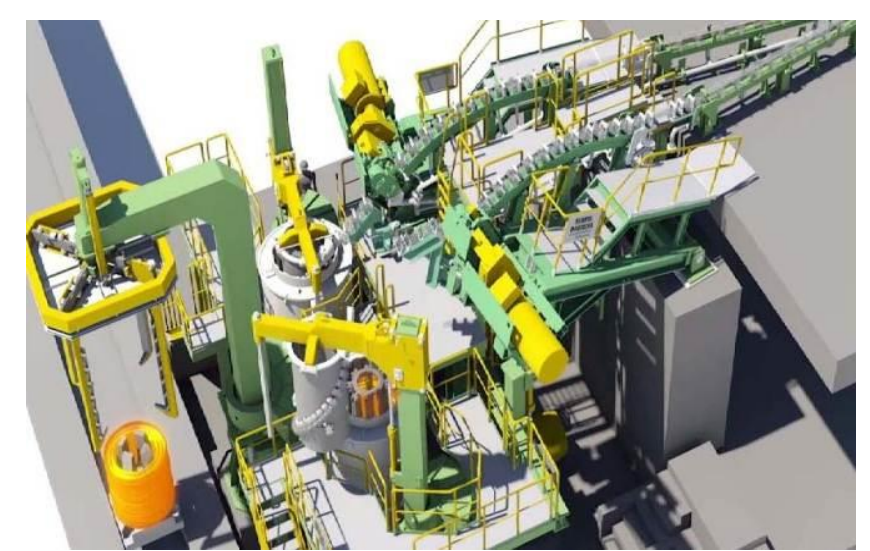

Figure 12: Pouring reel line arrangement at Fujian WuHang

The water cooling box is integrated and controlled by the Controlled Cooling Technology $\left(\mathrm{CCT}^{\circledR}\right)$ system which can be either operated in off-line or in on-line closed loop control.

The bar feed line is of highly wear resistant material. The U-shaped bar feed line with covers allows quick elimination of rolling material in case of a cobble.

For head and tail cropping as well as for sampling a shear is installed downstream the water cooling box.

After the shear a further switch is installed in order to guide the bar than into the individual pouring reel for the coiling process. Special attention has been paid for the location of the pinch roll.

In order to have an optimal supported coiling process, one individual pinch roll is installed as close as possible upfront each coiler drum on a lift able platform. Attached to the lift able platform is also the guiding trough which makes the connection to the spiral pipe laying system which guides the bar to be coiled to the bottom of the water cooled coiler drum.

The pinch roll arrangement, an advanced wobbling function as well as a stiff guiding steel structure assures a stable operation procedure which forms very dense coils up to $4000 \mathrm{~kg} / \mathrm{m}^{3}$.

In general special attention has been paid for a scratch free transport and guiding of the rolled bar in order to assure a smooth rolled material surface. Therefore the whole curved guiding system of the pouring reel line including the spiral pipe laying system is equipped with air/oil lubricated rollers. The pouring reels are equipped with wear strips on the inner pins and outer rotating drum to prevent mechanical damage during the formation of the coil (Figure 13).

An elevating coil plate assembly incorporated in the pouring reel removes the coil from the tub. The coil plate height is adjustable to provide optimum drum depths for each product size or range of sizes to ensure the coil is formed at the highest possible level to minimize the tail end length at the top of the formed coil.

\footnotetext{
* Technical contribution to the 51st Rolling Seminar - Processes, Rolled and Coated Products, October $28^{\text {th }}$ to $31^{\text {st }}, 2014$, Foz do Iguaçu, PR, Brazil.
} 


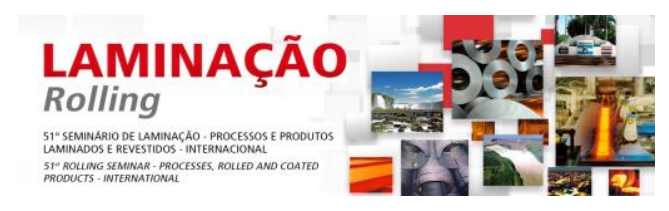

After the coiling process has been started the spiral pipe laying system is lifted according to the increasing coil height.

In order to avoid scratches after completion of the coiling process further measurements have been taken. Before the coil is lifted out of the water cooled coiling drum, the inner supporting and forming pins are collapsing and thus the compact coil can be lifted without harm out of the coiling drum by a hydraulic cylinder which is installed below each coil drum.

As soon as the coil is lifted out of the coiling drum the discharging system (Fig. 14), a so called sugar tong, hands the coil over to a pallet transport system for further processing in one of the most complex coil handling systems.

Various inline post treatment routes are possible at Fujian WuHang Stainless Steel Co., Ltd. as can be seen from the layout such as heat holding, quenching, online annealing and others. However, those are not further considered

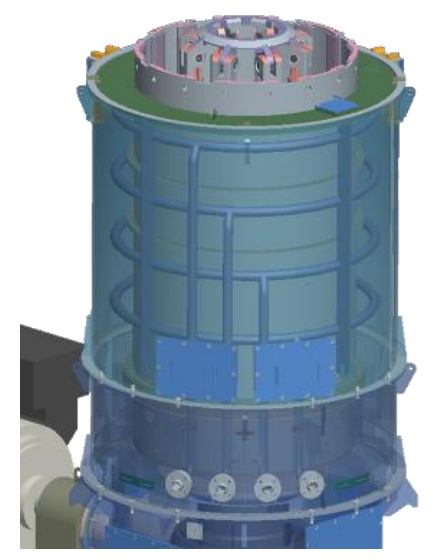

Figure 13: Water cooled pouring reel in this paper

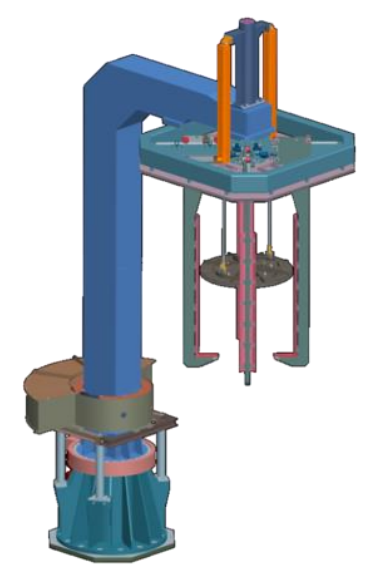

Figure 14: Coil discharging device

\section{CONCLUSION}

With pioneering spirit, courage and persistence revolutionary technological milestones have been introduced by SMS Meer into the market. More than 450 successfully installed wire rod and bar mills represent trust and great partnership of our customers.

The experience of the above mentioned installations in combination with the advanced 3-roll $\mathrm{PSM}^{\circledR}$ with hydraulic adjustment under load capability already stimulated the SBQ market. The indisputable process transparency of the 3-roll $\mathrm{PSM}^{\circledR}$ offers a wide field for further improving qualities of our customer's products. The great potential of the $\mathrm{PSM}^{\circledR} / \mathrm{MEER}$ gauge ${ }^{\circledR}$ combination still need to be further discovered.

The SMS Meer state of the art pouring reel line is the perfect completion of the advanced 3-roll technology for most modern SBQ production and an ideal combination. The improved coil formation and scratch free production of sensitive SBQ products is considered to offer highest flexibility and availability with minimum maintenance requirements.

The installation of the afore described key technologies for special bar quality and advanced wire rod production in demanding countries such as USA, Germany, China are indications for the huge potential of these new technologies. They are installed at

\footnotetext{
* Technical contribution to the 51st Rolling Seminar - Processes, Rolled and Coated Products, October $28^{\text {th }}$ to $31^{\text {st }}, 2014$, Foz do Iguaçu, PR, Brazil.
} 


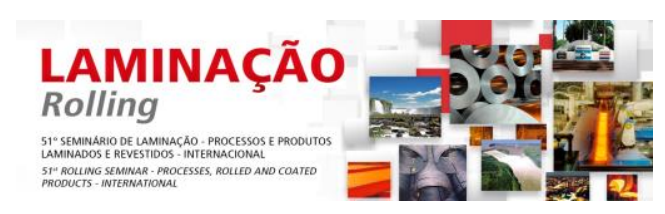

highly reputable steel producers which are in fierce competition in their individual market but also abroad.

Those superior technologies are inventive solutions to follow the todays and future demands of the individual markets. They are developed, designed, engineered and manufactured exclusively by SMS Meer based on a long experience in special quality steel production. This in combination with the vast process know how offers to our customers inimitable possibilities.

\section{REFERENCES}

1 Eisbach J, Helsper J. Dew Siegen, Practical experience with the world's first hydraulic adjustable 3-roll block for bars, International Steel Conference 2011, Duesseldorf, Germany, November 2011.

2 Helsper T, Jens Eisbach, DEW Siegen; Guenther Schnell, SMS Meer, The closed loop size control system in combination with the advanced 3-roll PSM at DEW SiegenGeisweid", 30 ${ }^{\text {th }}$ International Steel Industry Conference, Paris/France, December 2012.

* Technical contribution to the 51st Rolling Seminar - Processes, Rolled and Coated Products, October $28^{\text {th }}$ to $31^{\text {st }}, 2014$, Foz do Iguaçu, PR, Brazil. 